\title{
A brief history of solar-terrestrial physics in Australia
}

\author{
B. J. Fraser ${ }^{*} \mathbb{D}$
}

\begin{abstract}
Solar-terrestrial physics research in Australia began in 1792 when de Rossel measured the southern hemisphere geomagnetic field at Recherche Bay on the southern tip of Tasmania, proving the field magnitude and direction varied with latitude. This was the time when the French and British were competing to chart and explore the new world. From the early twentieth century Australian solar-terrestrial physics research concentrated on radio wave propagation and communication, which by the 1950s fed into the International Geophysical Year in the areas of atmosphere and ionosphere physics, and geomagnetism, with some concentration on Antarctic research. This was also the era of increased studies of solar activity and the discovery of the magnetosphere and the beginning of the space age. In the 1960s, Australia became a world leader in solar physics which led to radio astronomy discoveries. This paper outlines the historical development of solar-terrestrial physics in Australia and its international connections over the years and concludes with examples of specific research areas where Australia has excelled.
\end{abstract}

\section{Background}

Australia, being an isolated and relatively newly discovered continent, does not experience the advantages or disadvantages of Europe which is steeped in history. By the turn of the twentieth century Europe and the UK could claim over 800 years of well-established and successful University development in education and research. Correspondingly, Australia was a colony of the British Empire comprising a group of independent states which combined into the Commonwealth of Australia with a constitution in 1900 .

Internal communications were the first priority to be considered by the new nation, followed by reliable connections to the rest of the world. Then followed the disturbing war years, and more recently the space age, all of which bolstered the advancement of discovery and technology. Over these times, since the ionosphere and magnetosphere were discovered, solar-terrestrial physics (STP) was fundamental and made a vitally important contribution to this chain of events. Now in the twenty first century we are experiencing a rapid expansion of

\footnotetext{
*Correspondence: brian.fraser@newcastle.edu.au Centre for Space Physics, University of Newcastle, Callaghan, NSW 2308, Australia
}

digital and space technology, and this is providing opportunities to embark on large scale instrumentation accumulating and assimilating vast quantities of data never before imagined.

Due to space limitations this paper can only briefly outline the role STP played in Australia's development from a primitive colony to an advanced technology dependent country in just over two centuries. A fuller account of radio science and ionospheric research in the British Empire between the two world wars is included in Anduaga (2009). As well as being initially dependent on the UK some of Australia's experience involved New Zealand scientists and more detail on this has been provided by Fraser (2005). "The pre-1900s" section considers the beginnings of communications while "The twentieth century" section describes the early modern era where Australia takes advantage of high frequency communication leading into ionospheric research. Activities associated with Australian STP over the interval between the two world wars are covered in "Between the two world wars 1918-1939" section, while post world war II achievements are documented in "Post world war II: 1945-1980" section. Finally, "The modern era: post 1980" section considers the post 1980 era up to the present. This section is necessarily brief as most modern information is now 
available on specific institutional websites and online literature. Emphasis has been placed on the middle twentieth century, an extremely interesting time to be an STP researcher in Australia.

\section{The pre-1900s}

Following the Abel Tasman and James Cook discovery voyages a French expedition led by Bruni d'Entrecasteaux sent to find lost explorer La Perouse was caught in a storm in 1792 and sought refuge in Recherche Bay on the southeast tip of Van Diemen's Land, now Tasmania. Over the following 2 years, the d'Entrecasteaux expedition with physicist Elisabeth Paul Edouard de Rossi (male) undertook pioneering research of worldwide importance, showing that the geomagnetic field increased in strength with increasing latitude. Details of this work were reported by de Rossel (De Rossel 1808; Lilley and Day 1993). Without a method to directly measure the strength of the geomagnetic field the instrument of the time was a dip meter (Fig. 1a). The dip meter was set up vertically and stable, the needle set oscillating and the time for typically 100 oscillations recorded. Since the oscillation period, and consequently, the geomagnetic field strength varies with latitude this provided a simple method to compare field strength between hemispheres and with latitude. The period of oscillation was then plotted against dip angle as shown in Fig. 1b. The curve for an ideal geocentric dipole is superimposed for comparison. It is interesting to note that these measurements predate the Humboldt 1798-1803 South American observations (Humboldt and Biot 1804).

In nineteenth century Australia the six separate colonies relied on shipping to provide communication links between their widely dispersed coastal cities. In 1850, it took 60-80 days for mail to arrive from Europe. By 1859, Sydney, Melbourne, Adelaide and Tasmania were connected by telegraphic service. However, Australia needed to connect to the newly laid undersea telegraphic cable which connected England to Batavia (Jakarta) in Indonesia. An overland telegraph connection between Adelaide and the Port of Darwin was surveyed and constructed over 1870-1872 (Overland Telegraph 2015). The telegraph was successfully strung over $3200 \mathrm{~km}$ (Fig. 2a) using more than 36,000 wrought iron poles, placed $80 \mathrm{~m}$ apart with repeater stations every $250 \mathrm{~km}$. The signal was carried by one strand of number eight fencing wire (Fig. 2b), and powered by Meidinger gravity cell batteries, a forerunner to the common lead-acid battery. All repeater stations were manned fulltime by a telegraphist and maintenance staff. Needless to say, the line suffered many breakdowns in the harsh desert environment where thunderstorms were a problem. Parts of the
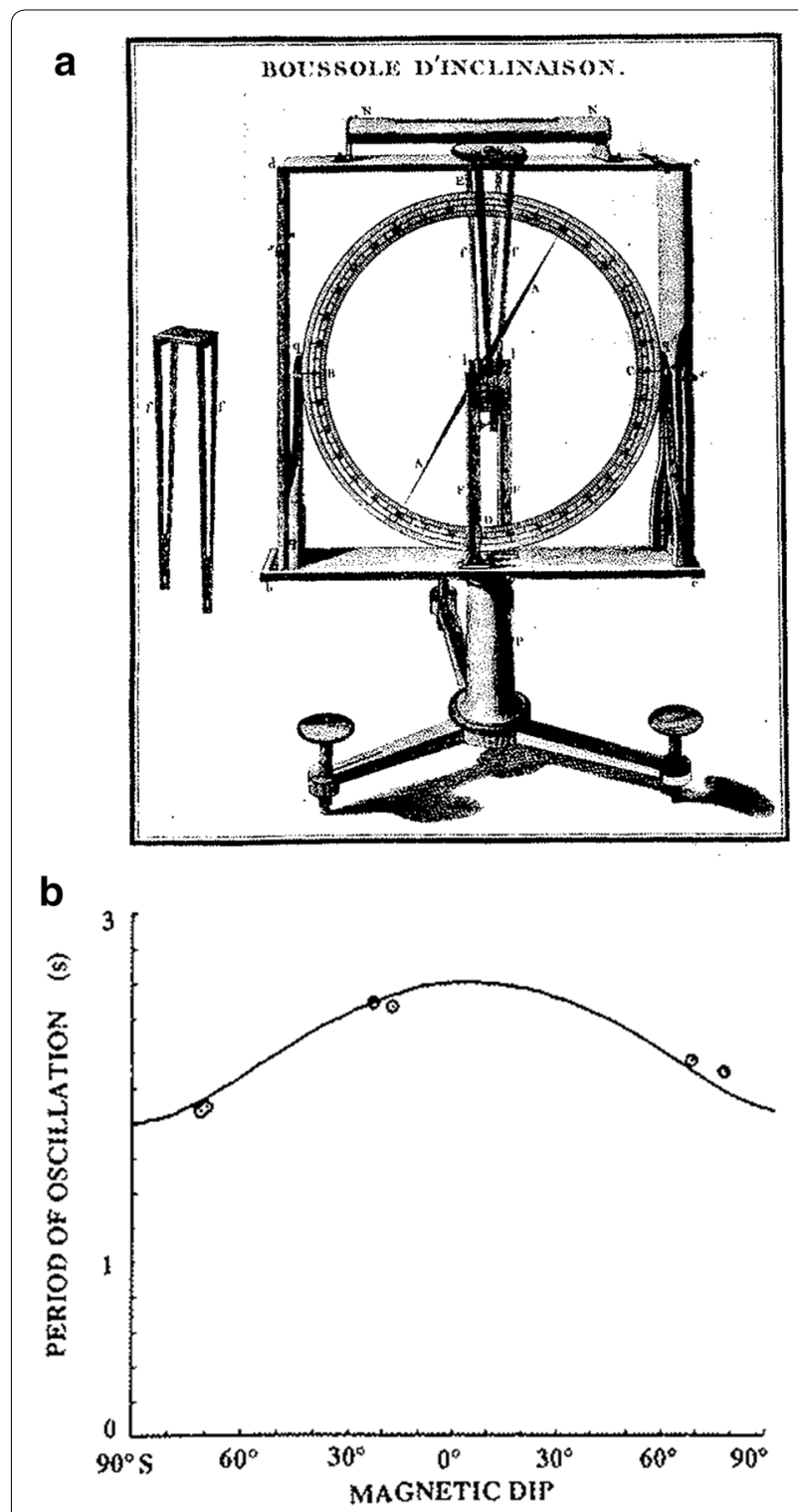

Fig. 1 a De Rossel's dip meter instrumentation 1792. b Period of oscillation variation with magnetic dip angle at various locations in latitude (after De Rossel 1808; from Lilley and Day 1993)

telegraph line were still being used until 1980, but there is no record of the Adelaide-Darwin line closure.

\section{The twentieth century}

\section{The importance of high frequency radio in Australia}

On 1 January 1901, Federation of the Australian colonies was achieved after a decade of planning. This established the Commonwealth of Australia as a Dominion of the British Empire. During the early years of the century, telegraphy continued to be the primary medium of communication over this vast country. Prior to about 1920, 
a

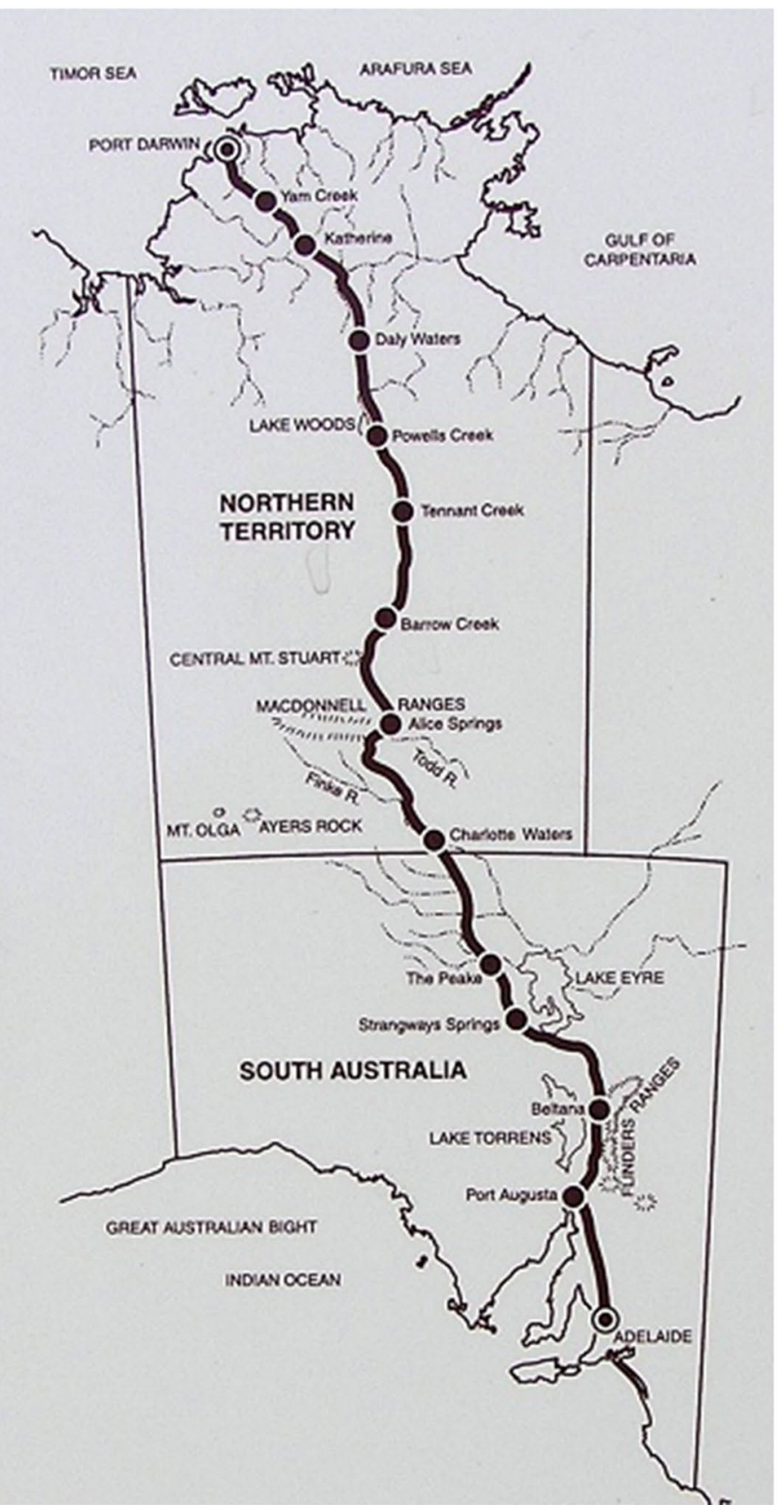

b

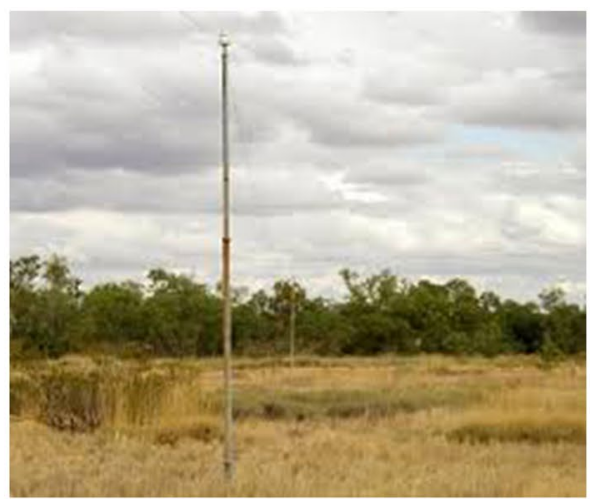

C

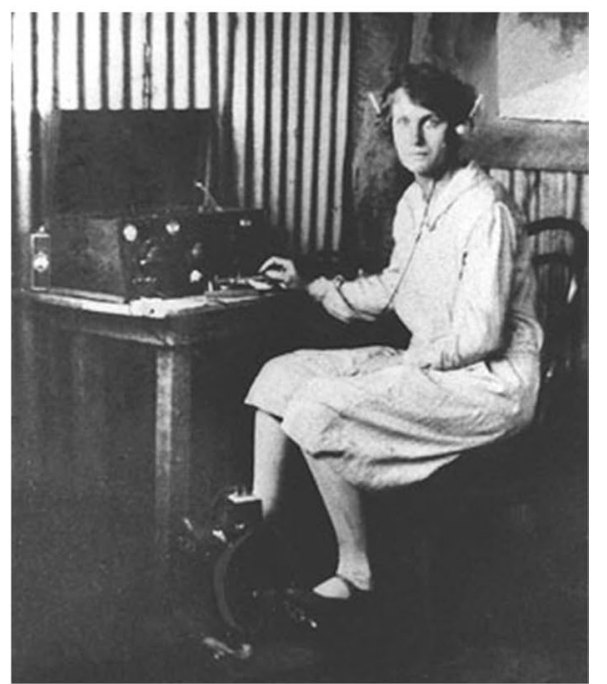

d

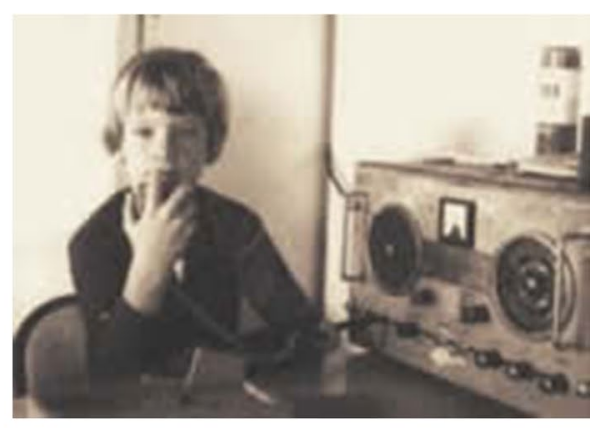

Fig. 2 a Overland telegraph route over Adelaide to Port Darwin 1870. b Overland telegraph poles with single wire and insulator. c Pedal radio circa 1930. d Transceiver circa 1960

most radio propagation experimentation took place at long and medium wavelengths. In the mid-1920s, it was realized that much shorter wavelengths could be used for long-distance propagation, which resulted, in 1926, of the introduction of shortwave high frequency (HF) wireless telegraphy stations, using relatively low power, and directional antennas (Padula 2015).
HF radio provided a means of communicating throughout Australia and to the rest of the world. News and other programs, including School of the Air to educate children in remote areas, were broadcast through Radio Australia. Typical early receiving systems are illustrated in Fig. 2c, d (Padula 2015). From the research as well as application point of view, the ionosphere and upper 
atmosphere became important in understanding the predictions of HF circuit conditions. Over the second half of the twentieth century, this will be seen to become even more important through aircraft navigation, defence applications, Antarctic and general communications, and over the horizon radar.

\section{Modern history}

After World War I, British science was redesigned to suit the political ideals of the British Empire. However, it was also noted that the Australian scenario was significantly different from the UK approach. For example, mining development was forging ahead using Australia's vast natural resources, and there was a need for efficient communications and aviation services spanning large distances.

The first direct evidence of the existence of electrified regions in the upper atmosphere was carried out by Appleton and Barnett in Southern England (Appleton and Barnett 1925). This experiment initiated the subsequent development of the major new science of upper atmosphere geophysics using radio waves. Australian scientists were to play an important role, both in England and at home, in the early discoveries. The Australian Federal Government established the Council for Scientific and Industrial Research (CSIR) in 1926 (White and Huxley 1975) and provided significant support funding. In the same year, the Australian Radio Research Board (ARRB) was established (White and Huxley 1975), following the British precedent (RRB-UK) which had just commenced research on the ionosphere, now a prestigious and autonomous discipline. The ARRB from 1927 was the first, using Australian Federal Government funding to sponsor university research. Two major research activities were supported. At the University of Sydney, John Madsen led extensive contributions to studies of the electrified regions of the atmosphere, now known as the ionosphere. The University of Melbourne under Thomas Laby devoted primary attention to "atmospherics" or lightning discharges, a major source of radio communication disturbance.

Following the establishment of the ARRB and up to the start of World War II, Australian physicists and engineers were becoming familiar with the variation in the properties of the ionosphere, particularly the vertical distribution of ionization and many interesting and important studies were published. David Martyn, a University of London graduate, was one of the four scientific officers selected to join the ARRB in 1929, and was assigned to Melbourne. Martyn was a complex man but an excellent theoretician. Early on he developed an important theorem showing information on obliquely incident waves, can be obtained from those of vertical incidence (Martyn 1935). Following a visit to the UK in the mid-1930s,
Martyn introduced UHF studies into Australia and was appointed head of the newly established ARRB Radio Physics Laboratory (RPL) at the University of Sydney.

The structure of research science management in Australia following the establishment of the CSIR and ARRB remained stable up until the end of World War II, when in 1949 the CSIR became the Commonwealth Scientific and Industrial Research Organisation (CSIRO) with a Division of Radiophysics absorbing the University of Sydney's RPL. By this time, the University of Melbourne's atmospheric program had closed down in 1939. To continue regular monitoring of ionospheric conditions following the end of the war, the Ionospheric Prediction Service (IPS) was established in 1947 for what has now become known as space weather forecasting, and is currently located within the Bureau of Meteorology (Space Weather Services 2015). Australia administers some $43 \%$ of the Antarctic continent and established permanent stations for upper atmosphere observations on the edge of the continent or nearby beginning in 1947 at Casey, Davis Mawson and Macquarie Island (Marchant et al. 2002). This provided Australian scientists with access to the high latitude outer regions of the magnetosphere from a low manmade noise environment.

\section{Between the two world wars 1918-1939}

Following the discovery of the ionosphere, Appleton and Ratcliffe (1928) predicted, according to magneto-ionic theory that radio waves which were left hand polarised in the northern hemisphere, should be right hand polarised in the southern hemisphere due to the oppositely directed geomagnetic field. This was confirmed by Green, of Madsen's Sydney Group in 1930 (Green 1932), although not comprehensively published until a few years later (Green 1934). Green also measured the height of reflection of the $E$ and $F$ ionospheric layers and found them consistent with the northern hemisphere (Green 1932). At this time technology was also developing, with Geoffrey Builder from Western Australia, travelling to the UK and undertaking postgraduate studies under Appleton (Appleton and Builder 1932). Returning to the Sydney Group Builder built an $80 \mathrm{~m}$ band pulse transmitter, installed at the University with a receiver at the southern Sydney suburb of Liverpool. The first equivalent heightfrequency ionograms in Australia were produced and provided to researchers by O. O. Pulley in 1935, a Sydney graduate under Madsen, while H. B. Wood in 1936 provided the first fully automated frequency sweep recorder covering 1.6-10 MHz in 5 min (Pulley 1934; Wood 1936). Figure 3 shows sweeps from 2.4 to $6 \mathrm{MHz}$ for the $\mathrm{O}$ wave in the upper panel and $\mathrm{X}$ wave in the lower panel. The critical frequencies of the $\mathrm{E}$ and F-regions can be seen at 120 and $210 \mathrm{~km}$, respectively. 

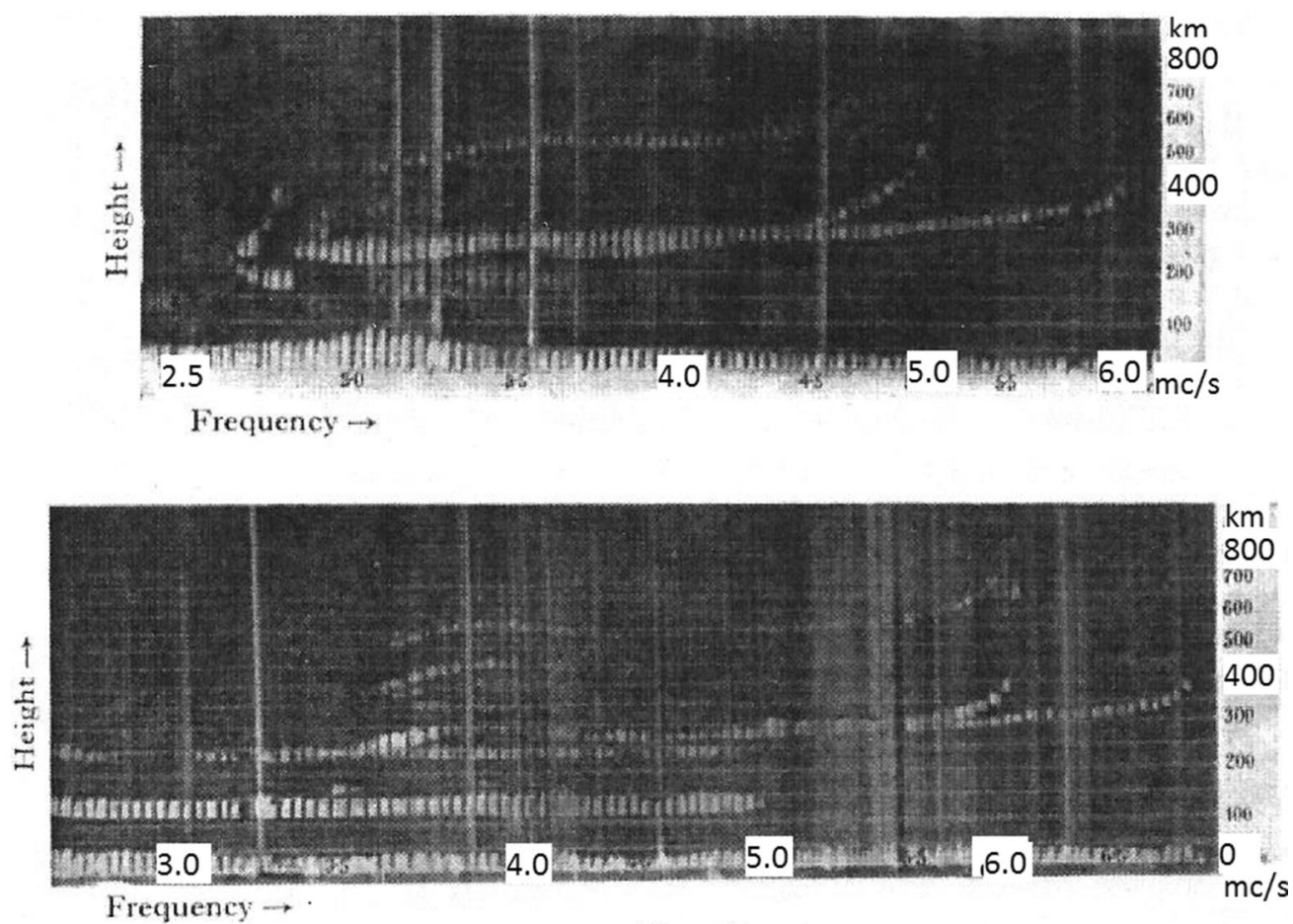

Fig. 3 An original ionogram from the first swept frequency ionosonde. Upper trace is O wave and lower trace the X mode (adapted from Pulley 1934)

Over this time, Victor Bailey at Sydney collaborated with Martyn in examining what was called the 'Luxemburg Effect'; the modulation of one wave travelling through the ionosphere by another. The effect is due to the nonlinear effects of the medium (Bailey and Martyn 1934).

The effects of solar disturbances on the ionosphere were also of interest to Australian radiophysicists engendered by collaboration between the Sydney Group and the Commonwealth Solar Observatory in Canberra. This was world's first research in solar variability understanding and associated ionospheric effects. In 1937, Martyn, George Munro, and colleagues reported that bright hydrogen emissions on the solar disk occurred almost simultaneously with an increase in ionospheric D-region absorption (Martyn et al. 1937). Munro, a New Zealander arrived in Sydney after spending time at Slough UK, found other ionospheric disturbances with durations of 10-60 min and showing a time lag in arrival between Canberra and Sydney corresponding to a speed of $5-10 \mathrm{~km} \mathrm{~s}^{-1}$. This was the discovery of the phenomenon travelling ionospheric disturbances (Munro 1950), which are now known as a signature of atmospheric gravity waves generated in the auroral thermosphere. Figure 4 from Munro (1950) shows ionospheric traces where virtual height dips and peaks and the crossover point of the
O and X rays. Over 1935-1937, Ron Giovanelli at the Solar Observatory was the first to recognise the relationship between sunspots and solar flares. The probability of flare occurrence was proportional to the sunspot group type, the group area and the rate of change of spot size (Giovanelli 1939).

\section{Post world war II: 1945-1980}

Over this period, Australia's STP research flourished with expansion of the National University System from 10 institutions in 1960 to 19 institutions in 1975, the injection of significant Federal government funding and the establishment of major research facilities. The STP field of study expanded too, from the ionosphere through the newly discovered magnetosphere and Van Allen radiation belts to solar radiation and radio astronomy where Australia became a world leader.

Other research programs were developing at this time. Ionosphere and atmosphere research flourished at the University of Adelaide, following the rich physics history of leadership under A. P. Rowe and L. G. H. Huxley. There Graham Elford and Basil Briggs established radar meteor research, MF and HF ionospheric research and radio astronomy all at the Buckland Park field site. Meanwhile, the newly established La Trobe University under Keith Cole, who previously worked with D. F. Martyn, 


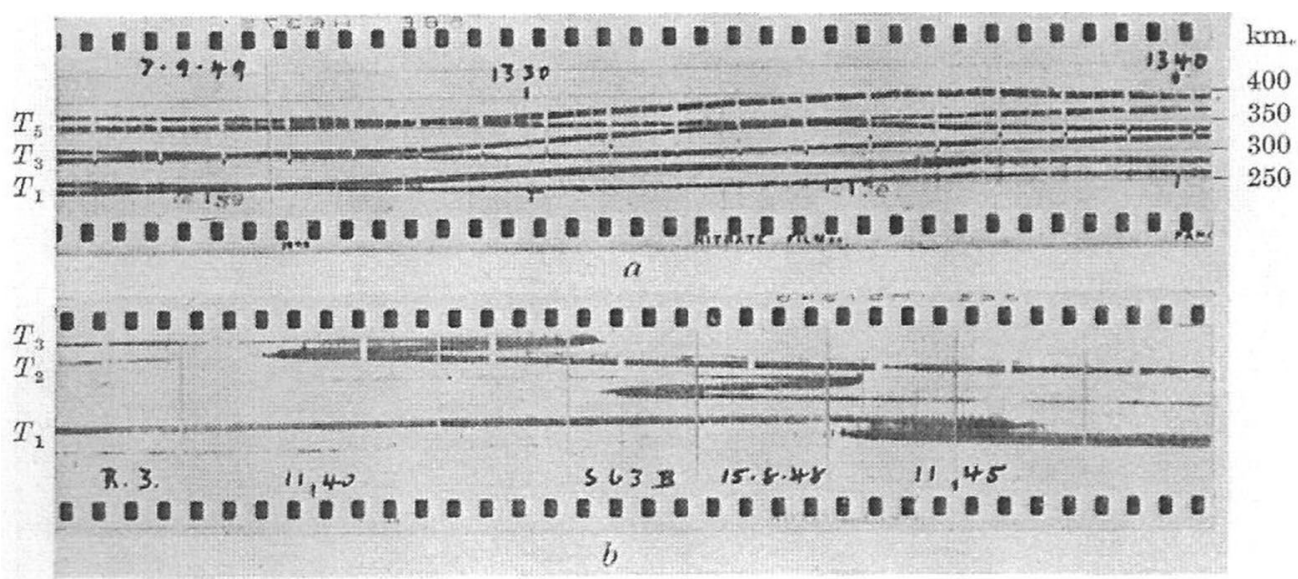

Fig. 4 a A typical record of a small travelling ionospheric disturbance (TID) from the $\mathrm{O}$ and $\mathrm{X}$ rays using 3 transmitters. $\mathbf{b}$ The Z-trace provides a more precise location of the event in time (Munro 1950)

undertook both theoretical and experimental ionospheric and magnetospheric research. An important finding by Cole (1962) was that Joule heating of the ionosphere by electric currents was a major source of energy input into the upper atmosphere. At the University of Queensland, Hugh Webster and David Whitehead established an ionospheric research program, concentrating on ionosonde research. The University of Newcastle NSW continued radar meteor research under Clif Ellyett and Colin Keay, begun earlier in NZ. Following a PhD degree under Appleton Jack Piddington returned to Madsen's group in Sydney and worked on radar development. At CSIRO, he later returned to theory concentrating on radio astronomy, astrophysics and magnetospheric physics, developing new ideas on solar wind-magnetosphere interaction and producing a closed magnetosphere model, similar to Axford and Hines; some years later a reflection on this model is given in Piddington (1979). In 1979, Don Melrose commenced research at Sydney University in the Centre for Astrophysics. Amongst his research into nonlinear plasma processes, he considered wave-particle interaction in magnetospheres (e.g. Melrose 1986).

\section{The beginning of radio astronomy}

During World War II most active Australian radiophysicists were seconded to radar or associated duties in the UK or locally for the Pacific war. Consequently, all radio and ionospheric researches were classified and not available to the scientific world. However, following the conclusion of the war some 300 or so radar experienced staff were available at the Radio Physics Laboratory (RPL) to recommence civilian scientific research.

Josef Pawsey an Australian, trained in the Cavendish Laboratory Cambridge under J. A. Ratcliffe returned home in 1940 to work at RPL as senior scientist.
Pioneering research led by Pawsey and Ruby Payne-Scott showed that strong variable solar radiation bursts originated near sunspots, causing disruptions to radio communications on Earth (Pawsey et al. 1946). At this time and in the foreseeable future, Australia became an international leader in this completely new field. Even at quiet times the Sun was found to send out a steady stream of radio waves from the corona with temperature $10^{6} \mathrm{C}$. Stimulated by these and other observations J. P. (Paul) Wild at Penrith, on the western edge of Sydney in 1949 developed the first solar radio spectrograph scanning $70-130 \mathrm{MHz}$ which produced a spectrum of frequencies every half second. One antenna element of the interferometer array is shown in Fig. 5a. It was the first instrument in the world able to detect the range of wavelengths contained in solar bursts (Wild and McCready 1950). Three types of solar radio bursts were identified of the now accepted international standard, and two are illustrated in Fig. 5b. Wild knew from previous ionospheric physics that the Sun's corona was analogous to the shells of an onion, each shell with its own resonant radio frequency, the highest frequency shells being closest to the Sun and the lowest the most distant from it. The spectrograph measured the resonant frequency of the bursts and so was able to identify the height of the source of radiation in the Sun's atmosphere at any instant. A Type I burst is a large complex stationary storm that hovers above a sunspot. Slow drifting radio bursts were first observed by Payne-Scott et al. (1947). They were later identified as type II bursts which occur a few times a month and are observed as shock waves moving at about a $1000 \mathrm{~km} \mathrm{~s}^{-1}$ to reach Earth in typically 1.5-2 days, producing bright auroral displays and great geomagnetic storms. Examples of original records of Type II bursts showing dispersion are illustrated in Fig. 5c. Type III bursts are common 
a

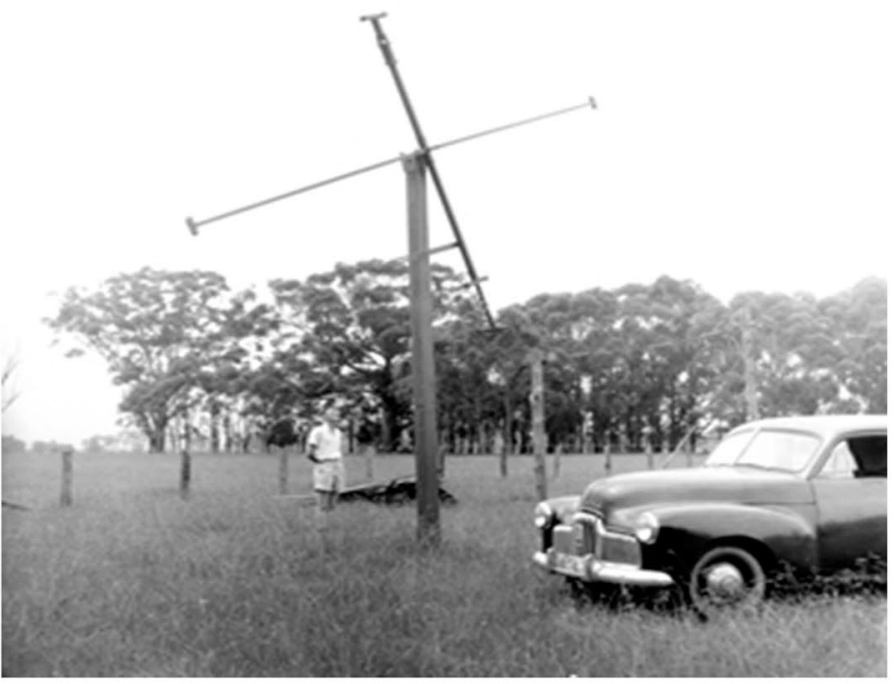

b

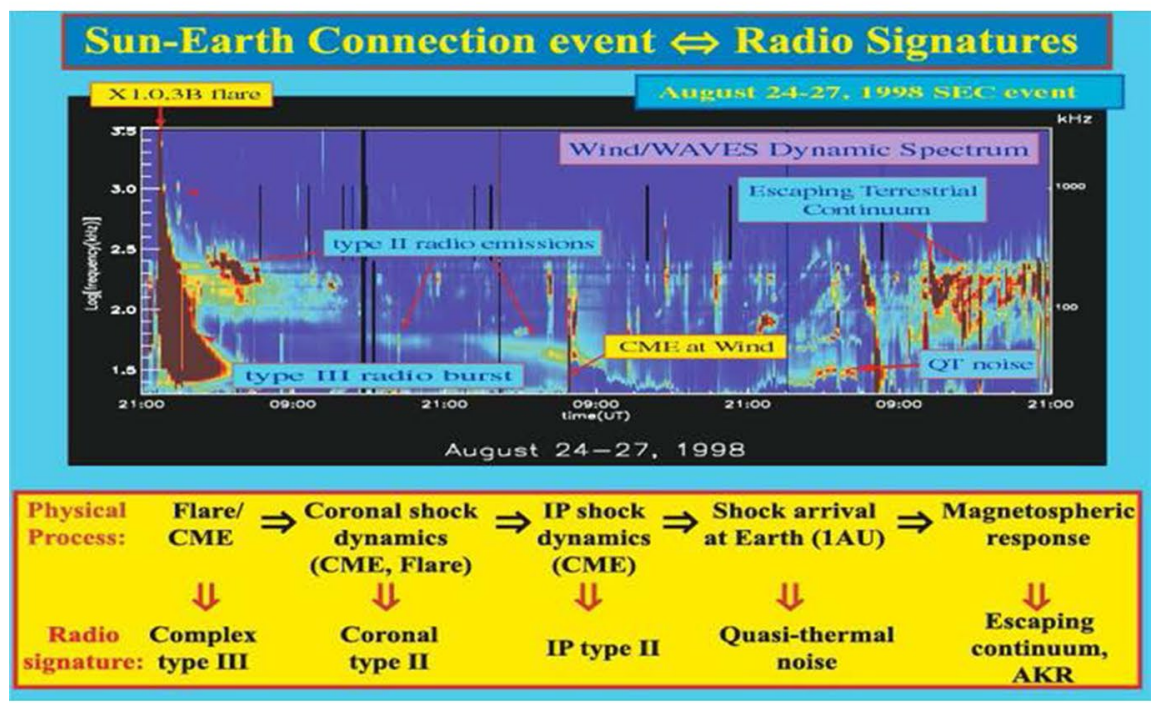

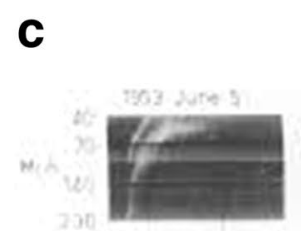

01325

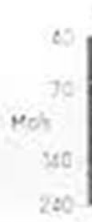

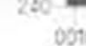

XS8 vetzex 4

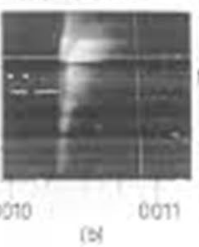

1055 Orcrmour 9

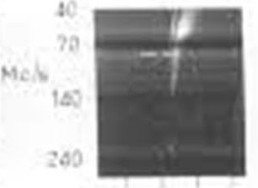

0.443

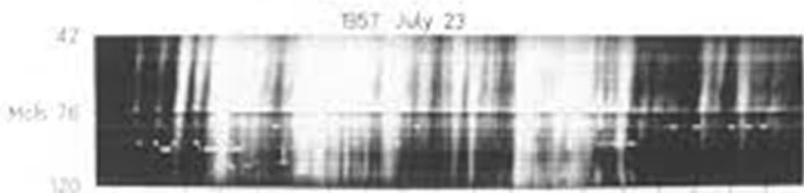

o145

0152

(d)

WVERSAL TME 
(See figure on previous page.)

Fig. 5 Solar Heliograph and radio bursts. a Original Dapto spectrograph antenna element 1949 (CSIRO 2013). b Spectrograph records of the four types of CME induced solar radio bursts commonly identified. c Type III solar radio bursts showing dispersion, harmonics and a group of bursts seen in the Dapto records. (https://csiropedia.csiro.au/radio-astronomy-observing-explosions-on-the-sun/)

but short lived, a radio flash lasting only a few seconds. The Wild's observations inferred that these flashes move at $10^{5} \mathrm{~km} \mathrm{~s}^{-1}$ sending electrons to Earth in only $30 \mathrm{~min}$ or so. Following the closure of Penrith a more advanced dynamic spectrograph was operated at Dapto, south of Sydney (1953-1963), and an interferometer giving full spatial information on radio bursts operated at Culgoora $480 \mathrm{~km}$ west of Sydney over 1967-1984. Culgoora Heliograph observations of type IV broadband continuum radio bursts combined with Mauna Loa K-coronameter data in white light resulted in the discovery of coronal transients (Hansen et al. 1971). This is the most important solar event that can cause severe space weather. The Culgoora instrument was succeeded by the Australia Telescope Compact Array at Narrabri in 1984. Instrument development continued and E.G. (Taffy) Bowen was largely responsible for the Parkes $64 \mathrm{~m}$ radio telescope, sponsored by the Australian Government, the Carnegie and Rockefeller Foundations, and used in the first US Moon landing. These two instruments are still at the forefront of Australian research today and are illustrated in Fig. 6.

Bowen worked on Air Warning and Airborne radar during World War II in the UK and the RPL in Sydney after 1944. He continued to work on air navigation which later resulted in the first civil aviation Distance Measuring Equipment (DME) and adopted for aircraft flying in Australia in 1953. Later over 1953-1978 Wild and colleagues designed and developed the Interscan Microwave Aircraft Landing System (Wild 1975) which was adopted internationally in 1978 and used until 1995 when the USA adopted the more accurate GPS for aircraft landing.

After WWII, Bowen worked on cloud and rain physics where dry ice seeding of clouds could produce rain, of vital importance to the dry Australian continent. Bowen also led the establishment of the $3.8 \mathrm{~m}$ Anglo-Australian optical telescope at Siding Springs in north-west New South Wales in 1974.

\section{International geophysical year 1957-1958}

The IGY was the birthplace of a new form of scienceInternational science, where collaboration between groups of nations finally led to the Antarctic Treaty signed in 1959, essentially preserving the territory for scientific exploration. This is one of the lasting outcomes of the IGY. For upper atmosphere and space physics, this human unpopulated low electrical noise environment provided an ideal natural laboratory while the high latitude location favours studies connected to the outer regions of the magnetosphere and polar cap.

\section{The modern era: post 1980}

In 1965, the Australian Government established the Australian Research Grants Scheme (ARGS) to provide project grants to support mostly basic research within the national university system. This agency was renamed the Australian Research Council (ARC) in 1988, and since then a wide range of grant categories have been established covering some 36 universities, government agencies and industry collaboration.
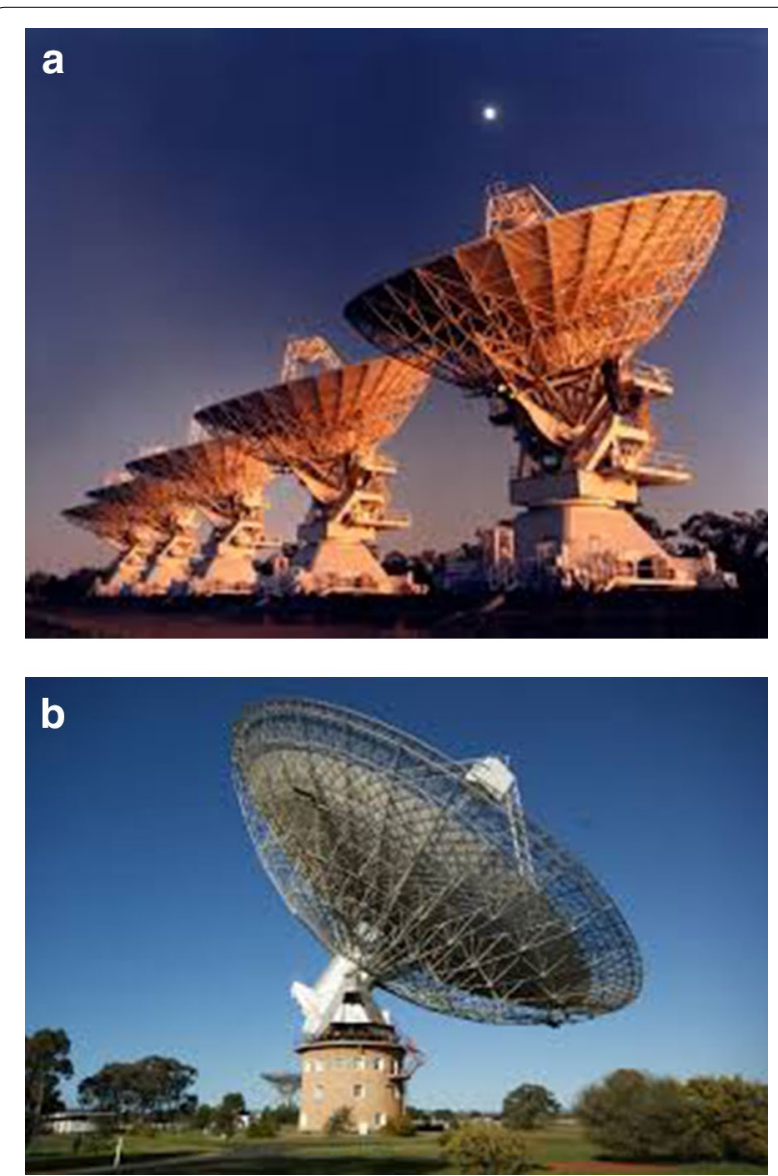

Fig. 6 a Australia Compact Array telescope, Narrabri, NSW. b Parkes radio telescope NSW (CSIRO Australia) 
Table 1 Recent and current research in STP being undertaken by Australian institutions and agencies

\begin{tabular}{|c|c|c|}
\hline Institution & Research interests & Reference \\
\hline $\begin{array}{l}\text { University of Adelaide Space \& Atmospheric } \\
\text { Physics }\end{array}$ & $\begin{array}{l}\text { Radar meteors; D-region; Lidar; MF/HFNHF/ST } \\
\text { radars; superDARN radar; Antarctic research }\end{array}$ & http://physsci.adelaide.edu.au/atmospheric/ \\
\hline La Trobe University Theoretical \& Space Physics & $\begin{array}{l}\text { E-F-Regions; ionospheric propagation \& cur- } \\
\text { rents; FedSat; SuperDARN radar; CRCSS; TEC; } \\
\text { ULF waves; photometers; Antarctic Research }\end{array}$ & $\begin{array}{l}\text { http://www.tiger.latrobe.edu.au/ } \\
\text { http://www.latrobe.edu.au/engineering/research/ } \\
\text { tiger }\end{array}$ \\
\hline University of Newcastle Centre for Space Physics & $\begin{array}{l}\text { Magnetospheric/ionospheric modelling; super- } \\
\text { DARN radar; FedSat; ULF-EMIC waves; riometer } \\
\text { absorption; CRCSS; Antarctic Research }\end{array}$ & $\begin{array}{l}\text { http://www.newcastle.edu.au/research-and- } \\
\text { innovation/centre/csp/ }\end{array}$ \\
\hline $\begin{array}{l}\text { University of NSW Astronomical and Space } \\
\text { Sciences }\end{array}$ & $\begin{array}{l}\text { Pico- and CubeSats; satellite communications \& } \\
\text { instrumentation; space debris }\end{array}$ & http://www.acser.unsw.edu.au/ \\
\hline DSTO Defence Science \& Technology & Jindalee \& JORN over horizon radar; FedSat & $\begin{array}{l}\text { http://www.dsto.defence.gov.au/innovation/ } \\
\text { jindalee-operational-radar-network }\end{array}$ \\
\hline Geoscience Australia & Observatories; geomagnetic data \& surveys & http://www.ga.gov.au/ \\
\hline University of Sydney Space \& Solar Physics & $\begin{array}{l}\text { Heliophysics; solar radio emissions; wave-particle } \\
\text { interactions; STEREO Mission; Murchison wide } \\
\text { field array; CubeSats }\end{array}$ & $\begin{array}{l}\text { http://sydney.edu.au/science/physics/space- } \\
\text { solar/ }\end{array}$ \\
\hline Australian Antarctic Division Space Weather & $\begin{array}{l}\text { Geomagnetic, iosospheric and auroral monitor- } \\
\text { ing; Riometry; Lidar; Cosmic Rays; SuperDARN; } \\
\text { spectrometers; photometers }\end{array}$ & $\begin{array}{l}\text { http://www.naa.gov.au/collection/fact-sheets/ } \\
\text { fs194.aspx } \\
\text { http://www.antarctica.gov.au/about-antarctica/ } \\
\text { environment/atmosphere }\end{array}$ \\
\hline Bureau of Meteorology Space Weather Services & $\begin{array}{l}\text { HF communications/surveillance; Geophysical } \\
\text { exploration; power systems/pipelines; satellite } \\
\text { operations; WDC solar-terrestrial science }\end{array}$ & http://www.sws.bom.gov.au/About_Sws \\
\hline
\end{tabular}

Two government grant schemes are available for the establishment of research centres: The ARC Centres of Excellence (CoE) and the Co-operative Research Centres (CRC) schemes. The ARC CoE involves research collaboration between universities, publicly funded research organisations, other research bodies, government and business. The CRC program supports industry driven research partnerships between publicly funded researchers, business and the community to address major long term challenges. The latter scheme established the CRC for satellite systems (CRCSS) which built and launched the microsatellite FedSat in 2002.

STP now falls under the more general umbrella of space science, and particularly space weather involving research on our Sun, the solar wind, earth's magnetosphere, ionosphere and atmosphere with an emphasis on protecting the earth's environment and associated technological systems from solar storm damage. Currently, space science in Australia is supported through 16 research universities and some 14 government institutions, across all states and the Capital Territory. Institutions where significant STP related research is undertaken nowadays are included in Table 1. There may be omissions from this table but a fuller up to date summary can be found elsewhere (National Committee for Space Science, 2010). Over the last 20 years, the various university research groups have been collaborating in a generally informal manner and activities do not overlap but tend to complement, providing the potential for an integrated national approach

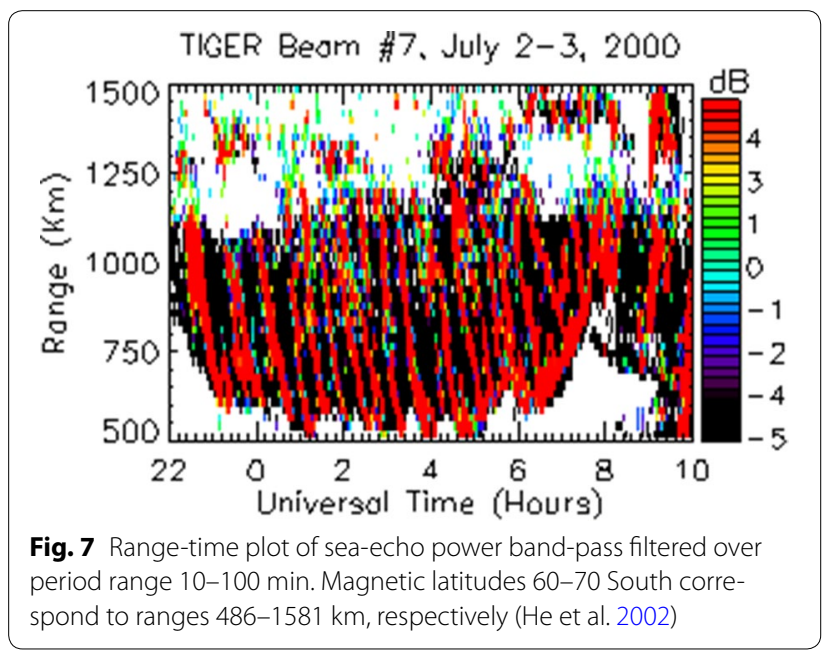

to STP research. These include Adelaide (Robert Vincent, Iain Reid), La Trobe (Peter Dyson) Newcastle (Brian Fraser), and Sydney (Iver Cairns).

Two projects over the last 20 years have attracted significant Federal funding. The Australian TIGER SuperDARN radar network consortium began in 2000 and undertook the first studies at low latitudes using SuperDARN radars (http://www.tiger.latrobe.edu.au). It comprises three radars, the original located on Bruny Island Tasmania, the second near Invercargill on the South Island of New Zealand, and the third at Adelaide South Australia. TIGER proved to be a very suitable 


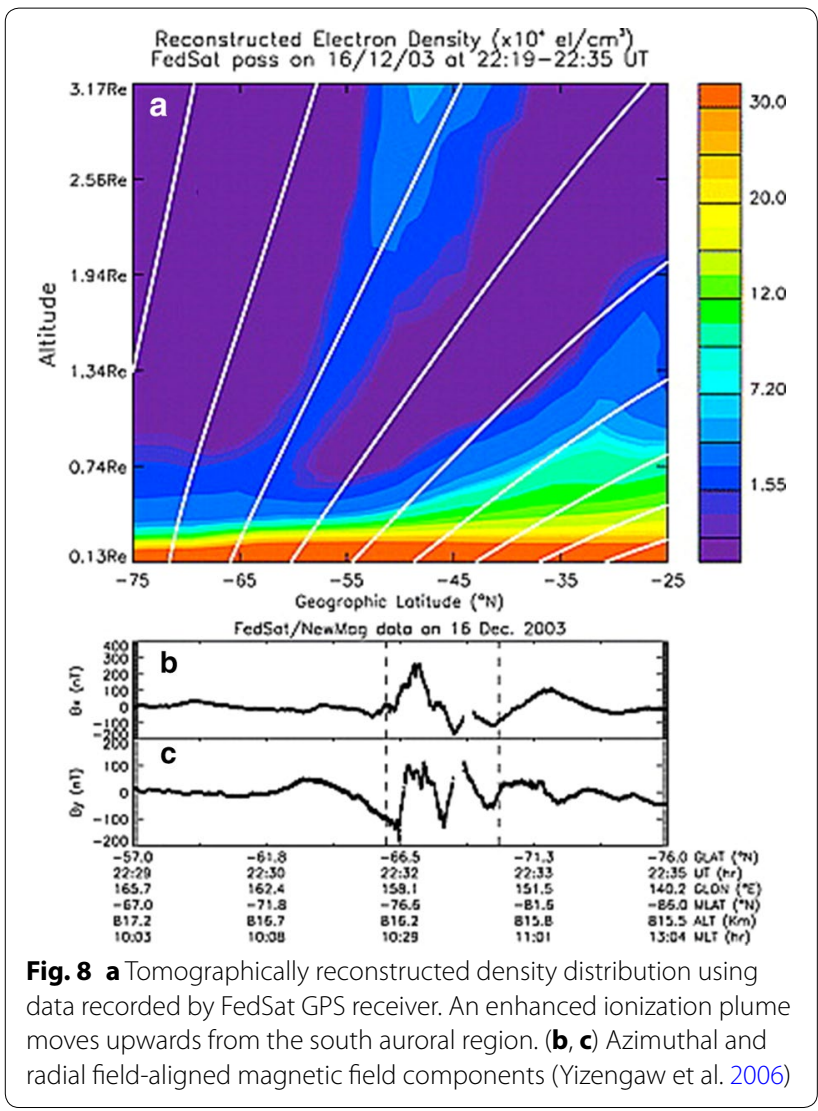

instrument for studying electric fields in the ionosphere, energy input into the auroral region, ultra low frequency (ULF) waves and atmospheric gravity waves originally recognised as TIDs by Munro (1950). A typical AGW seen by TIGER is shown in Fig. 7 (He et al. 2002). The FedSat project noted above and developed by the CRCSS was a $50 \mathrm{~kg}$ microsatellite launched into an $800 \mathrm{~km}$ Sunsynchronous polar orbit from Japan in December 2002, with a lifetime of $\sim 4$ years (https://www.aprsaf.org/ data/p_news/aus_afsp.pdf). Science payloads included a fluxgate magnetometer and GPS receiver. Amongst other achievements, FedSat studied the 3D structure of the plasmasphere using GPS and magnetometer data. Figure 8 shows a field-aligned plasma plume above the ionosphere (Yizengaw et al. 2006). More recently, an interesting new result pertaining to the effects of the plasmasphere on the reception of extraterrestrial HF radio waves on the ground has been the observation of geomagnetic field-aligned density ducts between the plasmasphere and ionosphere by Loi et al. (2015) and illustrated in Fig. 9. This was recorded by the Murchison Wide Field Array in Western Australia, a test cell for the future international Square Kilometre Array project (SKA 2015).

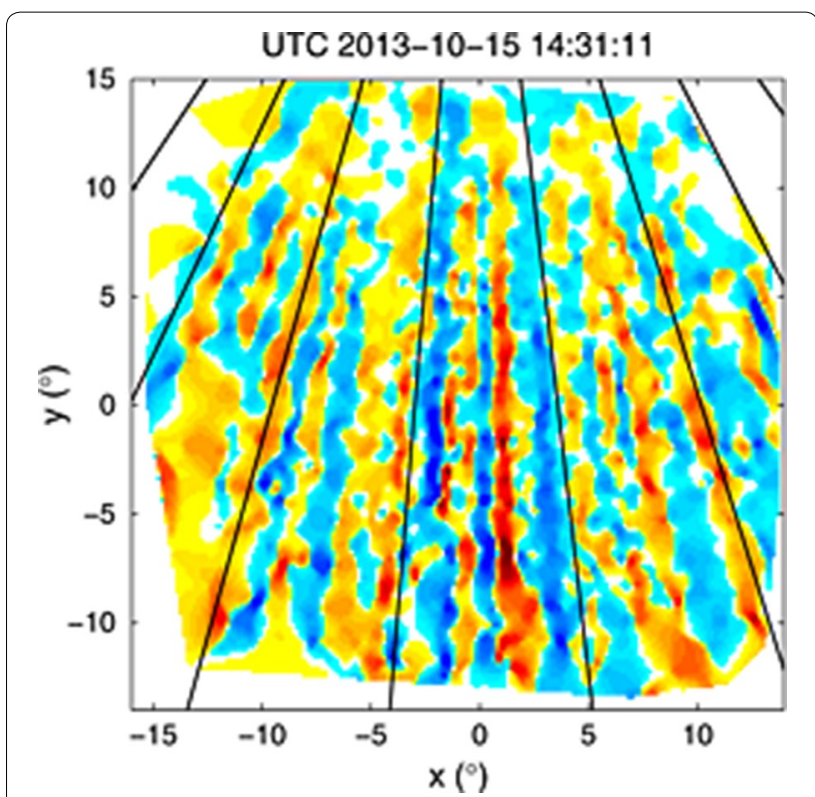

Fig. 9 Vector divergence plot showing plasmaspheric duct structure. Positive divergence regions (overdensities) represented by red-yellow hues; negative divergence regions (underdensities) by blue-cyan hues. White represents values close to zero (in FoV). Geomagnetic field lines overplotted as black lines (Loi et al. 2015)

\section{Conclusions}

Over more than one century beginning in the late 1800's, Australia has exhibited a rich history of achievement in solar-terrestrial physics, ranging from simple geomagnetic measurements to sophisticated radars and satellite payloads. These endeavours have been supported by competent and continuing theoretical and modelling programs. Beginning at the time of the Second World War applied research was fostered by close collaboration between UK, Australian and New Zealand physicists which later included the USA. As a consequence, great progress was made in association with the World War II effort and this continued through until the 1960's, and was a time when Australia was at the forefront of international STP research. An advantage over this period was, due the history evolving over the previous three decades that political implications were largely and conveniently absent from scientific planning and implementation. However, in the following three decades, until the end of the century, there was significant investment from the Australian Federal Government to expand research with applied research increasing, albeit supported with only modest private industry investment. In the new millennium, more emphasis has been placed on large projects. For example, the future multibillion dollar astronomical telescope, the Square Kilometre Array Project (SKA 2015) under development coupled with the 
need for detailed knowledge of ionospheric variability to interpret astronomical sky maps, suggests the possibility of a healthy decade or two of STP research ahead.

\section{Acknowledgements}

Support was provided by the University of Newcastle and the Centre for Space Physics. The following provided important information on historical and recent Australian STP research: Peter Dyson, Grahame Fraser, John Kennewell, lain Reid and Phil Wilkinson.

\section{Competing interests}

The author declares that there are no competing interests.

Received: 3 January 2016 Accepted: 4 June 2016

Published online: 18 July 2016

\section{References}

Anduaga A (2009) Wireless and Empire: geopolitics, radio industry and ionosphere in the British empire, 1918-1939. Oxford

Appleton EV, Barnett MAF (1925) Local reflection of wireless waves from the upper atmosphere. Nature 115:333-334

Appleton EV, Builder G (1932) Wireless echoes of short delay. Proc Phys Soc 44:76-87

Appleton EV, Ratcliffe JA (1928) On a method of determining the state of polarisation of downcoming wireless waves. Proc Roy Soc A117:576-588

Bailey VA, Martyn DF (1934) Interaction of radio waves. Nature 133:218

Cole KD (1962) A source of energy for the ionosphere. Nature 194:75

CSIRO (2013) https://csiropedia.csiro.au/ radio-astronomy-observing-explosions-on-the-sun/

De Rossel EPE (1808) Voyage de Dentrecasteaux, envoye a la recherche de La Perouse. de l'imprimerie imperiale Paris

Fraser GJ (2005) The antecedents and subsequent development of scientific radar in New Zealand. J Atmosph SolarTerrestr Phys 67:1411-1418

Giovanelli RG (1939) The relationship between eruptions and sunspots. Astrophys J 89:555-567

Green AL (1932) Council Scientific Industrial Research. Bull 59, Australia

Green AL (1934) The polarization of sky waves in the southern hemisphere. Proc IRE 22:324

Hansen RT, Garcia CJ, Grognard RM, Sheridan KV (1971) A coronal disturbance observed simultaneously with a white-light corona-meter and the $80 \mathrm{MHz}$ Culgoora radioheliograph. Proc Astronomical Soc Australia 2:57

He L, Dyson PL, Parkinson ML, Wilkinson PJ, Wan W (2002) Medium-scale travelling ionospheric disturbances studied with the TIGER SuperDARN Radar. WARS02 Proceedings Australian Academy of Science ISBN 0-9580476-0-X Paper G5, pp 1-6
Humboldt A, Biot J-B (1804) Sur Jes varia- tions du magnetisme terrestre a differentes latitudes. Phys 59:429

Lilley F, Day AA (1993) D'Entrecasteaux 1792: celebrating a bicentennial in geomagnetism. EOS Trans AGU 74:97-103. doi:10.1029/93EO00168

Loi ST et al (2015) Real-time imaging of density ducts between the plasmasphere and ionosphere. Geophys Res Lett 42:3707-3714. doi:10.1002/201 5GL063699

Marchant HJ, Lugg DJ, Quilty PG (eds) (2002) Australian Antarctic Science The first 50 years of ANARE. Australian Antarctic Division TAS Australia

Martyn DF (1935) The propagation of medium radio waves in the ionosphere. Proc Phys Soc 47:323. http://iopscience.iop.org/ article/10.1088/0959-5309/47/2/311/pdf

Martyn DF, Munro GH, Higgs AJ, Williams SE (1937) lonospheric disturbances, fadeouts and bright hydrogen solar eruptions. Nature 140:603-605. doi:10.1038/140603a0

Melrose DB (1986) Instabilities in space and laboratory plasmas. Cambridge University Press, Cambridge

Munro GH (1950) Travelling disturbances in the ionosphere. Proc Roy Soc A202:208-233

National Committee for Space Science (2010) Decadal plan for Australian Space Science. Australian Academy of Science Canberra. https://www. science.org.au/node/453

Overland Telegraph (2015) South Australian Government. http://www.australia.gov.au/about-australia/australian-story/overland-telegraph

Padula RJ (2015) History of shortwave radio in Australia. http://bpadula.tripod. com/australiashortwave

Pawsey JL, Payne-Scott R, McCready LL (1946) Radio-frequency energy from the Sun. Nature 157:158-159. doi:10.1038/157158a0

Payne-Scott R, Yabsley DE, Bolton JG (1947) Relative times of arrival of bursts of solar noise on different radio frequencies. Nature 160:256-257. doi:10.1038/160256bo

Piddington JH (1979) The closed model of the earth's magnetosphere. J Geophys Res 84:93-100. doi:10.1029/JA084iA01 p00093

Pulley OO (1934) A self-synchronized system for ionospheric investigation by the pulse method. Proc Phys Soc 46:853-871

SKA (2015) The square kilometre array. http://www.ska.gov.au/Pages/default. aspx

Space Weather Services (2015). http://www.sws.bom.gov.au/About_SWS, 2015

White FWG, Huxley LGH (1975) Radio research, Australia 1927-1939. Records of Australian Academy of Science 3:7-29. doi:10.1071/HR9750310007

Wild JP (1975) Interscan—basic concepts. IREECON'75, convention digest, $235-237$

Wild JP, McCready LL (1950) Observations of the spectra of high-intensity solar radiation at metre wavelengths. Aust J Sci Res 3:387-398

Wood HB (1936) J Inst Engrs Australia 17:403-414

Yizengaw E, Moldwin MB, Dyson PL, Fraser BJ, Morley S (2006) First tomographic image of ionospheric outflows. Geophys Res Lett 33:1944-8007. doi:10.1029/2006GL027698

\section{Submit your manuscript to a SpringerOpen ${ }^{\odot}$ journal and benefit from:}

- Convenient online submission

- Rigorous peer review

- Immediate publication on acceptance

- Open access: articles freely available online

- High visibility within the field

- Retaining the copyright to your article

Submit your next manuscript at $>$ springeropen.com 